\title{
Dampak Mekanisme Good Corporate Governance pada Carbon Emission Disclosure
}

\author{
I Dewa Gede Ngurah Eka Chandra \\ Pramuditya ${ }^{1}$ \\ Fakultas Ekonomi dan Bisnis \\ Universitas Udayana, Indonesia
}

\begin{abstract}
Surel : ekachandra16@gmail.com
ABSTRAK

Penelitian ini bertujuan untuk memahami dan mendapatkan bukti empiris perihal pengaruh kepemilikan institusional, kepemilikan asing, dewan komisaris indpenden, dan komite audit sebagai proksi Good Corporate Governance pada Carbon Emission Disclosure pada emiten sektor pertambangan yang tercatat di Bursa Efek Indonesia (BEI) 2014-2019. Penelitian ini menganalisa data penelitian memakai analisis regresi linier berganda. Berdasarkan data yang sudah dianalisis, kepemilikan institusional tidak berpengaruh pada Carbon Emission Disclosure, kepemilikan asing tidak berpengaruh pada Carbon Emission Disclosure, dewan komisaris independen tidak berpangaruh pada Carbon Emission Disclosure, dan komite audit berpengaruh positif pada Carbon Emission Disclosure.
\end{abstract}

Kata Kunci: Kepemilikan Institusional; Kepemilikan Asing; Dewan Komisaris Independen; Komite Audit; Carbon Emission Disclosure.

\section{The Impact of Good Corporate Governance Mechanism on Carbon Emission Disclosure}

\section{ABSTRACT}

The research's objective is to figure out and find empirical evidence regarding the influence of institutional ownership, foreign ownership, independent board of commissioners, and audit committee as Good Corporate Governance proxies on Carbon Emission Disclosure in mining sector companies registered on the Indonesia Stock Exchange (IDX) 2014-2019. This research analyzed the data by multiple linear regression analysis. Based on the data that has been analyzed, institutional ownership has no impact on Carbon Emission Disclosure, foreign ownership has no impact on Carbon Emission Disclosure, the independent board of commissioners has no impact on Carbon Emission Disclosure, and the audit committee has a positive impact on Carbon Emission Disclosure.

Keywords: Institutional Ownership; Foreign Ownership; Independent Board Of Commissioners; Audit Committee; Carbon Emission Disclosure.

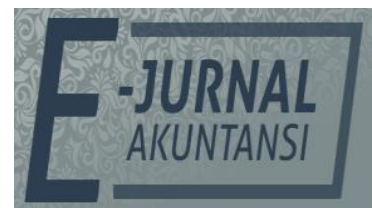

e-ISSN 2302-8556

Vol. 30 No. 12

Denpasar, Desember 2020

Hal. 3052-3065

DOI:

10.24843/EJA.2020.v30.i12.p05

PENGUTIPAN:

Pramuditya, I D.G.N.E.C. \& Budiasih, I G.A.N. (2020).

Dampak Mekanisme Good Corporate Governance pada

Carbon Emission Disclosure. EJurnal Akuntansi, 30(12), 3052-3065

RIWAYAT ARTIKEL:

Artikel Masuk: 12 Agustus 2020 Artikel Diterima: 8 Desember 2020

Artikel dapat diakses : https://ojs.unud.ac.id/index.php/Akuntansi/index 


\section{PENDAHULUAN}

Fenomena global warming sudah menyebabkan perubahan iklim serta kenaikan suhu yang terus meningkat tiap tahunnya. Menurut National Aeronautics and Space Administration (2019), didukung oleh penelitian Lenssen et al. (2019) menyatakan bahwa suhu bumi terus mengalami peningkatan dari tahun 1880 sampai dengan tahun 2018, serta mencapai suhu tertinggi pada tahun 2016. Peningkatan suhu tersebut melandasi pertemuan antar negara dalam membahas persetujuan tentang global warming atau emisi Gas Rumah Kaca (GRK), penyebab peningkatan suhu bumi ini. Persetujuan pertama yang dibuat oleh negara-negara di dunia adalah Protokol Kyoto pada tahun 1997. Halimah \& Yanto (2018) menyatakan bahwa setelah munculnya protokol tersebut, beberapa negara mulai meratifikasinya ke dalam bentuk undang-undang negara masingmasing, salah satunya Indonesia. Akan tetapi dari peraturan-peraturan yang ada, tidak ada satu pun peraturan yang mengatur kewajiban perusahaan agar mempertanggung jawabkan serta melaporkan emisi karbonnya khususnya kepada publik. Dengan demikian, Carbon Emission Disclosure perusahaan khususnya yang ditujukan kepada publik masih bersifat sukarela. Masih bersifat sukarelanya pengungkapan emisi karbon menyebabkan tidak banyak perusahaan di Indonesia yang melakukan Carbon Emission Disclosure. Hal tersebut dibuktikan melalui penelitian Pratiwi (2018) dari 91 perusahaan manufaktur dan pertambangan go public Indonesia, hanya 30 perusahaan yang melaporkan emisi karbonnya. Hasil yang sama didapatkan oleh Akhiroh \& Kiswanto (2016), dimana dari 52 emiten pengikut PROPER di luar sektor keuangan di Indonesia, hanya 32 emiten yang mengungkap emisi karbon perusahaannya.

Sedikitnya emiten yang melakukan pengungkapan emsisi karbon tentunya bertentangan dengan teori legitimasi. Kusumawardani \& Sudana (2017) menyatakan dalam teori legitimasi, perusahaan diasumsikan secara berkelanjutan harus menjamin bahwa operasi yang dilakukan perusahaan tidak menyimpang dari norma-norma di dalam masyarakat dan bisa dilegitimasi oleh pihak luar. Untuk mengatasi permasalahan ini, diperlukan pihak-pihak yang dapat mengawasi serta menekan perusahaan agar dapat melakukan Carbon Emission Disclosure secara optimal. Irmayanti \& Mimba (2018) menyatakan bahwa pihak-pihak yang mengawasi dan menekan perusahaan sudah dijelaskan dalam teori stakeholder, dimana perusahaan memerlukan dukungan para stakeholder nya dalam menjalankan operasinya. Teori ini juga didukung oleh teori agensi, dimana menurut Gitman (2007), dalam mengatasi permasalahan antara pihak principal serta pihak agen sebagai pemberi laporan, perusahaan dapat menggunakan agency cost yaitu biaya tambahan untuk meningkatkan pengawasan terhadap setiap tindakan manajer seperti biaya akan keberadaan dewan komisaris atau komite audit.

Permasalahan transparansi dan tanggung jawab/responsibilitas serta peran stakeholder dalam menangani permasalahan dalam perusahaan sudah disebutkan dan diatur dalam mekanisme Good Corporate Governance (GCG). Menurut Tamara \& Budiasih (2020), pengungkapan sosial dan lingkungan merupakan implementasi dari dua prinsip GCG yaitu responsibilitas dan tranparansi. Pengertian GCG menurut Forum Corporate Governance Indonesia, 
dalam Inastri \& Mimba (2017) adalah serangkaian sistem pengendalian dan pengawasan perusahaan melalui hubungan-hubungan yang terjalin antara para stakeholder perusahaan baik internal maupun eksternal.

Variabel GCG pada penelitian ini mengacu pada penelitian Akhiroh \& Kiswanto (2016) yang menggunakan mekanisme GCG dan diproksikan melalui variabel kepemilikan manajerial, kepemilikan institusional, komisaris independen dan komite audit sebagai pihak yang melaksanakan corporate governance pada perusahaan. Sementara itu kali ini kepemilikan manajerial diganti dengan mekanisme eksternal lainnya yaitu kepemilikan asing. Hal ini dijelaskan dalam Wulandari \& Sudana (2018) yang menyatakan bahwa dalam hal kepemilikan, persentase investor asing dalam suatu perusahaan relatif tinggi serta signifikan jumlahnya dibandingkan investor dari pihak manajemen.

Tabel 1. Emisi GRK Nasional Tahun 2008-2017

\begin{tabular}{cccccccc}
\hline \multirow{2}{*}{ Tahun } & \multirow{2}{*}{ Energi } & \multirow{2}{*}{ IPPU } & \multirow{2}{*}{ Pertanian } & FOLU & $\begin{array}{c}\text { Peat } \\
\text { Fire }\end{array}$ & Limbah & \multirow{2}{*}{ Total } \\
\cline { 2 - 8 } & $(\mathrm{Gg}$ & $(\mathrm{Gg}$ & $(\mathrm{Gg}$ & $(\mathrm{Gg}$ & $(\mathrm{Gg}$ & $(\mathrm{Gg}$ & $(\mathrm{Gg}$ \\
& CO2e $)$ & CO2e $)$ & CO2e $)$ & CO2e $)$ & CO2e $)$ & CO2e $)$ & CO2e $)$ \\
\hline 2008 & 391.784 & $36.498,63$ & 98.659 & 513.712 & 81.744 & 85.023 & 1.207 .421 \\
2009 & 405.653 & $37.546,31$ & 102.956 & 620.566 & 299.920 & 89.326 & 1.555 .967 \\
2010 & 453.235 & $36.032,83$ & 104.501 & 383.405 & 51.383 & 87.669 & 1.116 .226 \\
2011 & 507.357 & $35.910,40$ & 103.161 & 427.310 & 189.026 & 91.853 & 1.354 .617 \\
2012 & 540.419 & $40.077,58$ & 106.777 & 487.928 & 207.050 & 95.530 & 1.477 .782 \\
2013 & 496.030 & $39.109,53$ & 106.814 & 402.252 & 205.076 & 100.515 & 1.349 .797 \\
2014 & 531.142 & $47.488,95$ & 107.319 & 480.033 & 499.389 & 102.834 & 1.768 .206 \\
2015 & 536.306 & $49.297,37$ & 111.830 & 766.194 & 802.870 & 106.061 & 2.372 .558 \\
2016 & 538.025 & $55.307,45$ & 116.690 & 545.181 & 90.267 & 112.351 & 1.457 .821 \\
2017 & 558.890 & $55.394,51$ & 121.686 & 282.098 & 12.513 & 120.191 & 1.150 .773 \\
\hline
\end{tabular}

Sumber: Kementerian Lingkungan Hidup dan Kehutanan, 2019

Tabel 1, menunjukkan emisi karbon yang dihasilkan secara nasional tahun 2008-2017 berdasarkan enam sektor yaitu Energi, Industrial Process and Product Uses (IPPU), Pertanian, Food and Land Use (FOLU), Peat Fire (Kebakaran Lahan Gambut), serta Limbah. Pada Tabel 1, menunjukkan dari sepuluh tahun pengamatan emisi GRK di Indonesia, sektor Energi menjadi sektor penyumbang emisi karbon terbesar selama total enam tahun. Menurut Nasih et al. (2019), perusahaan energi dalam hal ini sektor pertambangan menggunakan sebagian besar energi dalam pengolahan produknya menggunakan bahan-bahan dari fosil yang dapat menghasilkan emisi karbon.

Berdasarkan teori stakeholder, investor institusional merupakan salah satu stakeholder perusahaan karena memiliki kepentingan akan eksistensi atau keberlangsungan perusahaan tersebut dalam jangka panjang. Kim \& Lyon (2011) dalam Akbaş \& Canikli (2019) menyatakan bahwa kesadaran investor institusional terhadap perubahan iklim akan meningkatkan nilai pemegang saham serta kesadaran manajemen akan pengungkapan isu lingkungan. Penelitian Jaggi et al. (2017), Nainggolan \& Rohman (2015), Pratiwi (2018), Akbaş \& Canikli (2019), serta Amaliyah \& Solikhah (2019), memperlihatkan bahwa 
kepemilikan institusional mempunyai pengaruh positif pada tingkat Carbon Emission Disclosure perusahaan.

$\mathrm{H}_{1}$ : Kepemilikan Institusional berpengaruh positif pada Carbon Emission Disclosure.

Teori legitimasi menyebutkan kebutuhan akan legitimasi dari masyarakat tidak hanya datang dari investor lokal tetapi juga investor asing terutama yang berada di perusahaan multinasional. Campbell et al. (2012) dalam Doś (2017) menyatakan komitmen perusahaan multinasional terhadap lingkungan dapat dilihat dari kebijakan non pasar anak perusahaan multinasional ini untuk mendapatkan legitimasi ketika beroperasi di negara host dimana stakeholders kurang familiar dengan perusahaannya. Hasil penelitian dari Dewi \& Suaryana (2015) di Indonesia, penelitian Doś (2017) pada perusahaan di Polandia serta Aleksic \& Boskovic (2017) pada perusahaan di Serbia, menunjukkan investor asing memiliki pengaruh positif pada pengungkapan lingkungan yang bersifat sukarela.

$\mathrm{H}_{2}$ : Kepemilikan Asing berpengaruh positif pada Carbon Emission Disclosure.

Berdasarkan stakeholder theory dalam Roberts (1992), dewan komisaris termasuk stakeholder karena merupakan sebuah kelompok yang dapat memberi dampak pada hasil tujuan perusahaan. Menurut Fitriana \& Prastiwi (2014), sesuai dengan teori agensi, dalam mengatasi agency problem, adanya komisaris yang bersifat independen dapat menekan pihak manajemen dengan fungsi pengawasan, sehingga dapat mendorong jajaran direksi untuk mengungkap halhal yang menyangkut kepentingan umum seperti emisi karbon sesuai dengan kepentingan pemegang saham. Dalam penelitian Niza \& Ratmono (2019) serta Nainggolan \& Rohman (2015), komisaris independen mempunyai pengaruh positif pada Carbon Emission Disclosure.

$\mathrm{H}_{3}$ : Dewan Komisaris Independen berpengaruh positif pada Carbon Emission Disclosure.

Roberts (1992) menyatakan bahwa dalam teori stakeholder, definisi stakeholder adalah kelompok yang dapat memberi atau terkena dampak terhadap tujuan perusahaan. Menurut Komite Nasional Kebijakan Governance (2006) melalui pedoman Good Corporate Governance yang diterbitkannya menunjukkan komite audit juga termasuk stakeholder karena perannya dalam membantu tugas dari komisaris perusahaan perihal pengawasan internal. Menurut Rafifah \& Ratmono (2015) hal ini sesuai dengan teori agensi, dimana semakin ketatnya pengawasan dapat mengurangi terjadinya manipulasi dan reduksi akan pengungkapan sehingga Carbon Emission Disclosure perusahaan yang bersifat sukarela semakin intensif dilakukan. Berdasarkan penelitian yang dilakukan oleh Akhiroh \& Kiswanto (2016), Amaliyah \& Solikhah (2019) dan Chariri et al. (2018) mengungkap bahwa anggota komite audit mempunyai pengaruh positif pada jumlah komponen-komponen emisi karbon perusahaan yang diungkapkan.

$\mathrm{H}_{4}$ : Komite Audit berpengaruh positif pada Carbon Emission Disclosure.

\section{METODE PENELITIAN}

Penelitian ini bertujuan untuk memahami dan mendapatkan bukti empiris perihal pengaruh dewan komisaris independen, kepemilikan asing, kepemilikan institusional, dan komite audit pada Carbon Emission Disclosure. Data-data pada 
penelitian ini didapatkan melalui situs BEI dan situs resmi perusahaan terkait pada periode 2014-2019.

Variabel kepemilikan institusional dihitung melalui rasio persentase kepemilikan perusahaan dari investor yang berasal dari pihak institusi dengan jumlah saham perusahaan yang beredar secara keseluruhan yang diperoleh dari annual report emiten terkait. Perhitungan kepemilikan institusional ini mengacu pada penelitian Halimah \& Yanto (2018) serta Hermawan et al. (2018) dengan rumus sebagai berikut.

Kepemilikan Institusional $=\frac{\sum \text { kepemilikansaham institusional }}{\sum \text { sahamyang beredar }} \times 100 \%$

Variabel kepemilikan asing dihitung melalui rasio persentase kepemilikan perusahaan dari investor asing dengan total saham yang beredar yang diperoleh dari annual report emiten terkait. Perhitungan kepemilikan institusional ini mengacu pada penelitian Irmayanti \& Mimba (2018) serta Singal \& Putra (2019) yang dijabarkan melalui rumus berikut.

Kepemilikan Asing $=\frac{\sum \text { kepemilikan saham olehasing }}{\sum \text { sahamyang beredar }} \times 100 \%$

Variabel dewan komisaris independen dihitung melalui rasio persentase komisaris independen dengan total anggota komisaris perusahaan yang didapat dari annual report emiten terkait. Perhitungan komisaris independen ini mengacu pada penelitian Nainggolan \& Rohman (2015) serta Salbiah \& Mukhibad (2018) dengan rumus sebagai berikut.

Dewan Komisaris Independen $=\frac{\text { Ekomisaris independen }}{\text { Eanggota dewankomisaris }} \times 100 \%$

Variabel komite audit dihitung melalui ukuran komite audit emiten yang didapat dari annual report emiten terkait. Perhitungan komite audit ini mengacu pada penelitian Niza \& Ratmono (2019) serta Budiharta \& Kacaribu (2020) dengan rumus sebagai berikut.

Komite Audit = total anggota komite audit

Perhitungan pengungkapan emisi karbon ini melalui checklist dari Choi et al. (2013). Checklist tesebut terdapat lima kategori yang berisi 18 item yang diberikan skor melalui skala dikotomi, dimana skor 1 untuk setiap pengungkapan satu item CED. Variabel Carbon Emission Disclosure dihitung dengan menjumlahkan seluruh item CED yang diungkapkan perusahaan. Itemitem tersebut diperoleh dari sustainability report perusahaan yang diterbitkan melalui situs resmi masing-masing perusahaan.

$C E D=$ total item yang diungkapkan

Penelitian ini menggunakan perusahaan sektor pertambangan go public Indonesia tahun 2014-2019 sebagai populasi. Penentuan sampel penelitian berdasarkan metode non probability sampling melalui teknik purposive sampling atau pencarian sampel melalui syarat-syarat tertentu. Adapun syarat-syarat yang menjadi penentu dalam sampling penelitian ini yakni emiten yang mempublikasikan annual report dan sustainability report secara konsisten dari tahun 2014-2019 dan emiten yang melampirkan data-data yang yang berkaitan dengan variabel-variabel secara keseluruhan. Pengumpulan data penelitian dilakukan melalui teknik dokumentasi. Penelitian ini menganalisa data penelitian memakai analisis regresi linier berganda. 


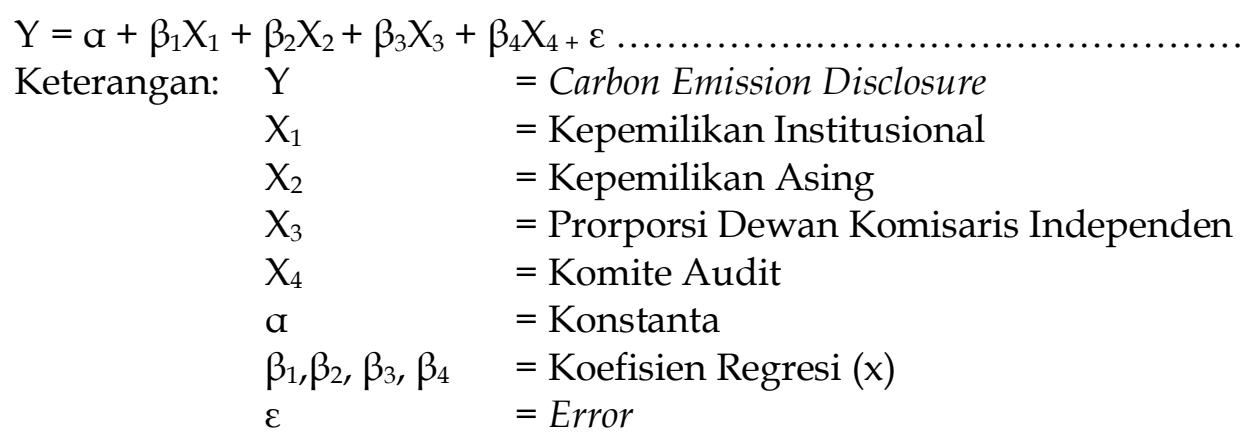

\section{HASIL DAN PEMBAHASAN}

Berdasarkan sampling yang telah dilakukan pada penelitian ini maka diperoleh total emiten yang menjadi sampel yaitu enam emiten. Jadi jumlah pengamatannya adalah 36 observasi. Analisis statistik deskriptif yang dapat dilihat pada Tabel 2, menunjukkan informasi perihal karakteristik kelima variabel yang terdapat pada penelitian ini diantaranya total observasi, nilai yang paling kecil, nilai yang paling besar, nilai mean dan standar deviasi dari suatu variabel.

Tabel 2. Hasil Analisis Statistik Deskriptif

\begin{tabular}{lccccc}
\hline & $\mathrm{N}$ & Minimum & Maximum & Mean & Std. Deviation \\
\hline Kepemilikan Institusional & 36 & 69,80 & 98,10 & 88,2667 & 8,30898 \\
Kepemilikan Asing & 36 & 0,00 & 90,44 & 35,1658 & 37,84038 \\
Dewan Komisaris Independen & 36 & 30,00 & 50,00 & 35,7389 & 4,88766 \\
Komite Audit & 36 & 3 & 4 & 3,61 & 0,494 \\
Carbon Emission Disclosure & 36 & 1 & 14 & 8,44 & 3,410 \\
Valid N (listwise) & 36 & & & &
\end{tabular}

Sumber: Data Penelitian, 2020

Sebelum melakukan analisis regresi linier berganda, terlebih dahulu perlu untuk dilakukannya uji asumsi klasik terhadap model penelitian agar dapat memenuhi asumsi-asumsi dasar di dalam analisis regresi. Uji asumsi klasik untuk penelitian ini terdiri dari uji normalitas, uji multikolinieritas, uji autokorelasi, dan uji heterokedastisitas..

Tabel 3. Hasil Uji Normalitas

\begin{tabular}{|c|c|c|}
\hline \multicolumn{2}{|c|}{$x^{2}+x^{2}$} & Unstandardized Residual \\
\hline $\mathrm{N}$ & & 36 \\
\hline \multirow[t]{2}{*}{ Normal Parametersa,b } & Mean & 0,0000000 \\
\hline & Std. Deviation & 2,57732684 \\
\hline \multirow[t]{3}{*}{ Most Extreme Differences } & Absolute & 0,068 \\
\hline & Positive & 0,063 \\
\hline & Negative & $-0,068$ \\
\hline Test Statistic & & 0,068 \\
\hline Asymp. Sig. (2-tailed) & & $0,200^{c, d}$ \\
\hline
\end{tabular}

Sumber: Data Penelitian, 2020

Hasil pada uji normalitas yang ditunjukkan oleh Tabel 3, menggunakan Uji Kolmogorov Smirnov. Hasil pada tabel tersebut memperlihatkan bahwa nilai Asymp. Sig. (2-tailed) lebih besar dari 0,05. Hasil tersebut mengungkapkan bahwa data pada model regresi penelitian sudah terdistribusi normal. 
Tabel 4. Hasil Uji Multikolinieritas

\begin{tabular}{lcc}
\hline \multirow{2}{*}{ Model } & \multicolumn{2}{c}{ Collinierity Statistics } \\
\cline { 2 - 3 } & Tolerance & Variance Inflation Factor \\
\hline Kepemilikan Institusional & 0,317 & 3,158 \\
Kepemilikan Asing & 0,541 & 1,848 \\
Dewan Komisaris Independen & 0,660 & 1,516 \\
Komite Audit & 0,505 & 1,981 \\
\hline
\end{tabular}

Sumber: Data Penelitian, 2020

Hasil uji multikolinieritas pada Tabel 4, memiliki fungsi untuk memeriksa ada atau tidaknya korelasi antar variabel independen dalam model regresi. Hasil pada tabel tersebut memperlihatkan tidak adanya variabel independen yang mendapat nilai Tolerance lebih kecila dari 0,1 dan nilai VIF lebih besar dari sepuluh. Maka dapat disimpulkan model regresi penelitian ini terbebas dari gejala multikolinieritas.

Tabel 5. Hasil Uji Autokorelasi

\begin{tabular}{lllll}
\hline $\mathrm{R}$ & $\mathrm{R}$ Square & $\begin{array}{l}\text { Adjusted } \mathrm{R} \\
\text { Square }\end{array}$ & $\begin{array}{l}\text { Std. Error of the } \\
\text { Estimate }\end{array}$ & Durbin-Watson \\
\hline 0,655 & 0,429 & 0,355 & 2,739 & 1,312 \\
\hline
\end{tabular}

Sumber: Data Penelitian, 2020

Hasil pada uji normalitas yang ditunjukkan oleh Tabel 5, menggunakan Uji Durbin Watson. Tabel 5, memperlihatkan bahwa dari hasil uji yang didapatkan, nilai Durbin-Watson bernilai sebesar 1,312. Dengan jumlah variabel sebanyak 5 $(\mathrm{k}=5)$ dan observasi sebanyak $40(\mathrm{t}=40)$, maka nilai $\mathrm{d}_{\mathrm{L}}=1,23583$ dan $\mathrm{d}_{\mathrm{U}}=1,72447$. Berdasarkan hal tersebut dapat disimpulkan bahwa $d$-statistic berada di antara $d_{L}$ dan $\mathrm{d}_{\mathrm{U}}(1,23583<1,312<1,72447)$ sehingga ada atau tidaknya gejala autokorelasi tidak dapat diketahui secara pasti. Dalam mengatasi permasalahan tersebut maka untuk mengungkap dan memastikan gejala autokorelasi yang terdapat pada model regresi, dilaksanakan Uji Runs Test.

\section{Tabel 6. Hasil Uji Runs Test}

\begin{tabular}{lc}
\hline & Unstandardized Residual \\
\hline Test Value & $-0,05267$ \\
Cases $<$ Test Value & 18 \\
Cases $>=$ Test Value & 18 \\
Total Cases & 36 \\
Number of Runs & 16 \\
Z & $-0,845$ \\
Asymp. Sig. (2-tailed) & 0,398 \\
\hline
\end{tabular}

Sumber: Data Penelitian, 2020

Tabel 6, mengungkap bahwa nilai Asymp. Sig. (2-tailed) bernilai 0,398 lebih besar dari 0,05. Jadi bisa ditarik kesimpulan bahwa model regresi penelitian ini tidak memiliki gejala atau masalah autokorelasi.

Tabel 7. Hasil Uji Heteroskedastisitas

\begin{tabular}{lc}
\hline Model & Sig. \\
\hline Kepemilikan Institusional & 0,613 \\
Kepemilikan Asing & 0,231 \\
Dewan Komisaris Independen & 0,203 \\
Komite Audit & 0,052 \\
\hline
\end{tabular}

Sumber: Data Penelitian, 2020 
Uji heterokedastisitas penelitian ini dilakukan dengan memakai Uji Glejser. Hasil yang diperlihatkan oleh Tabel 7, mengungkapkan bahwa besarnya tingkat signifikansi variabel-variabel independen melebihi tingkat signifikansi 0,05, dimana dapat ditarik kesimpulan bahwa tidak adanya gejala heterokedastisitas pada model regresi penelitian.

Tabel 8. Hasil Analisis Regresi Linier Berganda

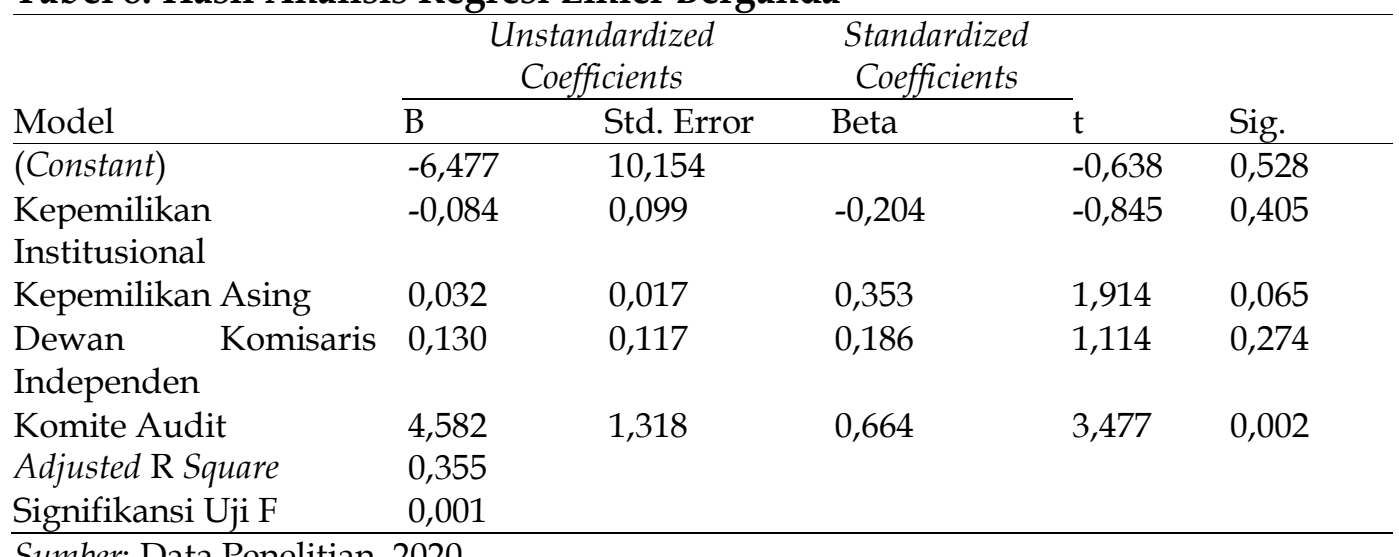

Sumber: Data Penelitian, 2020

Analisis regresi linier berganda pada Tabel 8, menghasilkan model regresi sebagai berikut.

$$
Y=-6,477-0,084 X_{1}+0,032 X_{2}+0,130 X_{3}+4,582 X_{4}
$$

Model regresi tersebut memperlihatkan konstanta sebesar -6,477 yang dapat diartika jika kepemilikan institusional, kepemilikan asing, dewan komisaris independen, dan komite audit bernilai 0 maka nilai Carbon Emission Disclosure atau variabel Y menjadi sebesar -6,477. Kepemilikan institusional 0,084 memiliki pengertian bahwa jika kepemilikan institusional bertambah 1 satuan dapat menyebabkan nilai Carbon Emission Disclosure menjadi turun -0,084 satuan dengan anggapan bahwa variabel yang lain nilainya konstan. Kepemilikan asing 0,032 memiliki pengertian bahwa jika kepemilikan asing bertambah 1 satuan dapat mengakibatkan nilai Carbon Emission Disclosure bertambah 0,032 satuan dengan anggapan variabel yang lain nilainya konstan. Dewan komisaris independen 0,130 memiliki pengertian bahwa jika dewan komisaris independen bertambah 1 satuan dapat mengakibatkan nilai Carbon Emission Disclosure menjadi bertambah 0,130 satuan dengan anggapan variabel yang lainnya nilainya konstan. Komite audit 4,582 memiliki pengertian bahwa jika komite audit bertambah 1 satuan dapat mengakibatkan Carbon Emission Disclosure bertambah 4,582 satuan dengan anggapan variabel yang lain nilainya konstan.

Tabel 8, memperlihatkan bahwa signifikansi Uji F bernilai 0,001, dimana dengan tingkat signifikansi (a) sebesar 5 persen atau 0,05 menjadikan nilai signifikansi Uji F $(0,001)$ lebih kecil dari pada 0,05. Berdasarkan hal tersebut, dapat disimpulkan bahwa variabel-variabel indpenden penelitian yaitu kepemilikan institusional, kepemilikan asing, dewan komisaris independen, dan komite audit secara simultan memiliki pengaruh pada variabel dependen yaitu Carbon Emission Disclosure.

Tabel 8, mengungkapkan bahwa Adjusted $R^{2}$ memiliki nilai 0,355 yang memiliki arti bahwa 35,5\% variansi dari variabel terikat, yakni Carbon Emission 
Disclosure dapat dijelaskan oleh variansi variabel terikat penelitian ini, yakni kepemilikan institusional, kepemilikan asing, dewan komisaris independen, dan komite audit, sedangkan $64,5 \%$ sisanya dijelaskan oleh faktor-faktor selain yang ada dalam model penelitian ini.

Tabel 8, memperlihatkan bahwa koefisen regresi variabel kepemilikan institusional bernilai negatif sebesar $-0,084$ dengan signifikansi uji $\mathrm{t}$ yang bernilai 0,405, dimana hal ini menunjukkan nilai signifikansinya lebih besar dari 0,05. Jadi dapat diartikan bahwa kepemilikan institusional tidak berpengaruh pada Carbon Emission Disclosure.

Berdasarkan hasil dari analisis data pada penelitian ini, dapat diartikan bahwa meskipun dengan persentase investor institusional yang tinggi, tidak berarti perusahaan akan lebih memperhatikan isu-isu lingkungan yang terjadi pada masyarakat umum dalam upaya mendapatkan legitimasi untuk menaikkan nilai perusahaan. Investor institusi masih merasa bahwa Carbon Emission Disclosure kurang mampu meningkatkan nilai perusahaan dibandingkan faktor lainnya seperti likuiditas maupun profitabilitas perusahaan, sehingga tingginya persentase kepemilikan institusional tidak akan memengaruhi pelaksanaan Carbon Emission Disclosure. Hasil dari penelitian tersebut didukung dengan dua penelitian terdahulu yaitu Akhiroh \& Kiswanto (2016) serta Hermawan et al. (2018). Menurut Hermawan et al. (2018), karena pengungkapan emisi karbon merupakan pengungkapan sukarela, maka keputusan ada atau tidaknya Carbon Emission Disclosure berada di tangan manajemen. Sukarelanya Carbon Emission Disclosure menyebabkan manajemen menentukan diungkapkan atau tidaknya emisi karbon perusahaan berdasarkan keuntungan yang didapat apabila informasi emisi karbon perusahaan diungkap.

Tabel 8, memperlihatkan bahwa koefisien regresi variabel kepemilikan asing bernilai positif sebesar 0,032 dengan signifikansi uji t yang bernilai 0,065, dimana hal ini menunjukkan nilai signifikansinya lebih besar dari 0,05. Jadi dapat diartikan bahwa kepemilikan asing tidak berpengaruh pada Carbon Emission Disclosure.

Hasil pada analisis data ini dapat diartikan bahwa tingkat investor asing yang rendah menyebabkan investor asing menjadi tidak memiliki pengaruh terhadap kebijakan perusahaan dalam melakukan pengungkapan emisi karbon atau isu perubahan iklim. Hal ini membuktikan bahwa investor asing yang berasal dari negara yang telah menerapkan Carbon Emission Disclosure atau lebih aktif dalam isu lingkungan, belum tentu dapat memberikan pengaruh terhadap pengungkapan-pengungkapan bersifat sukarela karena tidak memiliki pengaruh yang dominan terhadap pengambilan keputusan perusahaan, sehingga kepemilikan asing tidak dapat memengaruhi Carbon Emission Disclosure perusahaan. Hal ini menurut Singal \& Putra (2019) yang juga meneliti perusahaan di sektor pertambangan, bahwa kepemilikan asing tidak memiliki pengaruh pada pengungkapan yang berkaitan dengan lingkungan sebab emiten pada sektor pertambangan merupakan perusahaan dengan kategori high profile. Perusahaan dengan kategori high profile memiliki sensitivitas yang tinggi terhadap isu lingkungan dikarenakan adanya persaingan bisnis yang ketat sehingga perusahaan menjadi berhati-hati dalam melakukan pengungkapan isu lingkungan khususnya emisi karbon atau perubahan iklim. 
Tabel 8, memperlihatkan bahwa koefisien regresi variabel dewan komisaris independen bernilai positif sebesar 0,130 dengan signifikansi uji $\mathrm{t}$ yang bernilai 0,274, dimana hal ini menunjukkan nilai signifikansinya lebih besar dari 0,05. Jadi dapat diartikan bahwa dewan komisaris independen tidak berpengaruh pada Carbon Emission Disclosure.

Hasil pada pengolahan data penelitian ini memperlihatkan rata-rata persentase komisaris independen pada perusahaan yang rendah sehingga pengaruh dari independennya seorang komisaris tidak mampu membuat manajemen merasa tertekan untuk melakukan Carbon Emission Disclosure. Dewan komisaris yang independen atau berarti tidak memiliki keterikatan dengan perusahaan, dimana mereka lebih memerhatikan kepentingan masyarakat luas seperti isu perubahan iklim dibandingkan komisaris yang terafiliasi dengan perusahaan menjadi tidak berpengaruh karena kurang optimalnya pengaruh komisaris independen dalam menekan manajemen melakukan pengungkapanpengungkapan sukarela, sehingga persentase dari komisaris independen tidak memiliki pengaruh pada pelaksanaan pengungkapan emisi karbon perusahaan. Hasil dari penelitian tersebut didukung dengan penelitian-penelitian terdahulu seperti Akhiroh \& Kiswanto (2016), Amaliyah \& Solikhah (2019), Kılıç \& Kuzey (2019), dan Salbiah \& Mukhibad (2018). Menurut Amaliyah \& Solikhah (2019), tidak berpengaruhnya dewan komisaris independen pada tingkat Carbon Emission Disclosure karena dewan komisaris independen adalah pihak dari luar perusahaan, dimana berarti komisaris independen memiliki keterbatasan waktu dalam melaksanakan tugas yang diberikan perusahaan kepadanya sehingga pengawasan terhadap perusahaan menjadi kurang optimal.

Tabel 8, memperlihatkan bahwa koefisien regresi variabel komite audit bernilai positif sebesar 4,582 dengan signifikansi uji t yang bernilai 0,002, dimana hal ini menunjukkan nilai signifikansinya lebih kecil dari 0,05. Jadi dapat diartikan bahwa komite audit berpengaruh positif pada Carbon Emission Disclosure.

Dewan komisaris membentuk suatu komite audit yang bertugas mengawasi pelaporan atau pengungkapan yang ada dalam laporan manajemen serta melakukan audit internal secara menyeluruh terhadap hal-hal yang terkait dengan pengungkapan atau pelaporan. Apabila manajemen melakukan hal-hal yang tidak diinginkan sesuai hasil RUPS seperti melakukan pengungkapan emisi karbon, maka komite audit berhak menindak lanjuti temuannya sesuai dengan wewenang yang diberikan oleh perusahaan. Jadi apabila jumlah anggota komite audit kian bertambah, maka semakin luas Carbon Emission Disclosure yang dilakukan perusahaan. Hasil dari penelitian tersebut didukung dengan penelitian sebelumnya seperti penelitian dari Akhiroh \& Kiswanto (2016), Amaliyah \& Solikhah (2019), serta Chariri et al. (2018). Menurut Chariri et al. (2018), meningkatnya jumlah anggota komite audit mampu mendorong perusahaan agar mengungkap informasi-informasi yang berkaitan dengan lingkungan seperti mengenai emisi karbonnya secara lebih baik. Adanya komite audit membuat pengawasan terhadap manajemen menjadi lebih baik dan dapat menekan manajemen agar bertindak memperhatikan dampak lingkungannya.

Berdasarkan teori stakeholder, adanya komite audit memberikan tekanan bagi para manajemen untuk melakukan pengungkapan seluas-luasnya mengenai 
kinerja perusahaan, termasuk kinerja lingkungannya khususnya dalam hal perubahan iklim. Gitman (2007) menyatakan agency cost merupakan salah satu solusi dalam menekan terjadinya agency problem dalam perusahaan. Komite audit sendiri merupakan salah satu agency cost tersebut sehingga dengan lebih banyaknya komite audit, perusahaan mampu mengatasi masalah asimetri informasi dengan memberikan pengawasan terhadap manajemen agar melakukan pengungkapan lingkungan khususnya mengenai emisi karbon.

\section{SIMPULAN}

Berdasarkan hasil pengolahan data, kepemilikan institusional tidak berpengaruh pada Carbon Emission Disclosure. Tingginya persentase kepemilikan investor institusi terhadap emiten tidak mempunyai pengaruh pada tingkat pengungkapan emisi karbon perusahaan. Hasil penelitian yang sama terjadi pada kepemilikan asing yang disimpulkan tidak berpengaruh pada Carbon Emission Disclosure. Hasil pengolahan data mengungkapkan kepemilikan asing yang rendah tidak mampu memengaruhi keputusan mengenai Carbon Emission Disclosure di perusahaan. Dewan komisaris independen juga disimpulkan tidak berpengaruh pada Carbon Emission Disclosure. Rendahnya rasio komisaris independen pada perusahaan menyebabkan tidak mampunya dewan komisaris independen memengaruhi pengungkapan emisi karbon perusahaan. Sedangkan komite audit dari analisis data dan pembahasan dalam penelitian bisa ditarik kesimpulan memiliki pengaruh positif terhadap Carbon Emission Disclosure. Artinya, semakin besar ukuran komite audit pada suatu perusahaan dapat menyebabkan semakin terbukanya perusahaan dalam mengungkap informasi mengenai emisi karbonnya.

Berdasarkan penjabaran dari hasil penelitian ini, terdapat beberapa saran baik kepada peneliti selanjutnya maupun kepada pihak perusahaan dan regulator yang dapat disampaikan. Bagi peneliti selanjutnya, sebaiknya melakukan pengamatan pada annual report perusahaan juga, melihat sedikitnya jumlah perusahaan khususnya sektor pertambangan yang mengeluarkan sustainability report. Selain itu, dilihat dari analisis koefisien determinasi yang hanya 35,5\%, maka peneliti selanjutnya bisa mengubah proksi Good Corporate Governance dengan variabel lain atau melalui hasil dari Corporate Governance Perception Index (CGPI) serta pengukuran-pengukuran GCG lainnya. Hasil penelitian menunjukkan rata-rata kepemilikan asing perusahaan relatif rendah, maka disarankan untuk menambah variabel kontrol seperti jenis perusahaan atau menambah kriteria sampling terkait dengan kepemilikan asing. Peneliti juga bisa mengubah proksi dari pengukuran variabel ini melihat hasil dari pengukuran pada variabel dewan komisaris independen relatif rendah dan mirip antara perusahaan satu dengan perusahaan lainnya.

Bagi perusahaan, khususnya perusahaan pertambangan diharapkan untuk meningkatkan kualitas corporate governance nya serta intensitas Carbon Emission Disclosure nya melalui konsistensi pelaporan sustainability report nya, sebagai kontribusi awal untuk membantu Indonesia dalam mengurangi emisi GRK dan menciptakan lingkungan bisnis yang sehat serta berkelanjutan. Bagi regulator, untuk dapat menerapkan regulasi baik umum maupun khusus untuk perusahaan sektor pertambangan khususnya agar wajib melaporkan 
sustainability report nya serta wajib diisikan informasi mengenai emisi karbon yang dihasilkan masing-masing perusahaan, untuk ikut berkontribusi dalam isu perubahan iklim serta menciptakan kualitas corporate governance yang baik terutama bagi perusahaan pertambangan yang go public.

\section{REFERENSI}

Akbaş, H. E., \& Canikli, S. (2019). Determinants Of Voluntary Greenhouse Gas Emission Disclosure: An Empirical Investigation On Turkish Firms. Sustainability (Switzerland), 11(107), 1-24. https:// doi.org/10.3390/su11010107

Akhiroh, T., \& Kiswanto. (2016). The Determinant Of Carbon Emission Disclosures. Accounting Analysis Journal, 5(4), 326-336.

Aleksic, V. S., \& Boskovic, A. (2017). The Influence Of Foreign Ownership On Corporate Social Responsibility In Serbian Companies. In M. Cingula, M. Przygoda, \& K. Detelj (Eds.), International Scientific Conference on Economic and Social Development Madrid (Vol. 23, Issue 63, pp. 645-652). Varazdin: Varazdin Development and Entrepreneurship Agency.

Amaliyah, I., \& Solikhah, B. (2019). Pengaruh Kinerja Lingkungan dan Karakteristik Corporate Governance Terhadap Pengungkapan Emisi Karbon. Journal of Economic, Management, Accounting and Technology (JEMATech), 2(2), 129-141. https:// doi.org/10.32500/jematech.v2i2.720

Budiharta, P., \& Kacaribu, H. E. P. B. (2020). The Influence of Board of Directors, Managerial Ownership, and Audit Committee on Carbon Emission Disclosure: A Study of Non-Financial Companies Listed on BEI. Review of Integrative Business and Economics Research, 9(3), 75-87.

Chariri, A., Januarti, I., \& Yuyetta, E. N. A. (2018). Audit Committee Characteristics and Carbon Emission Disclosure. E3S Web of Conferences, 73(02001), 1-5. https:/ / doi.org/10.1051/e3sconf/20187302001

Choi, B. B., Lee, D., \& Psaros, J. (2013). An Analysis Of Australian Company carbon emission disclosures. Pacific Accounting Review, 25(1), 58-79. https:// doi.org/10.1108/01140581311318968

Dewi, N. P. M. S., \& Suaryana, I. G. N. A. (2015). Pengaruh Profitabilitas Dan Kepemilikan Asing Pada Pengungkapan Corporate Social Responsibility. E-Jurnal Akuntansi, 13(1), 84-98.

Doś, A. (2017). The Effect Of Foreign Equity Ownership On Corporate Social Responsibility: Empirical Evidence From Poland. E-Finanse, 13(3), 66-75. https:/ / doi.org/10.1515/fiqf-2016-0030

Fitriana, N. L., \& Prastiwi, A. (2014). Faktor-Faktor Yang Mempengaruhi Luas Pengungkapan Sukarela Dalam Annual Report. Diponegoro Journal of Accounting, 3, 642-651.

Gitman, L. J. (2007). Principles of Managerial (10th ed.). Massachusett: AddisonWesley.

Halimah, N. P., \& Yanto, H. (2018). Determinant Of Carbon Emission Disclosure At Mining Companies Listed In Indonesia Stock Exchange. KnE Social Sciences, 3(10), 127-141. https://doi.org/10.18502/kss.v3i10.3124

Hermawan, A., Aisyah, I. S., Gunardi, A., \& Putri, W. Y. (2018). Going Green: Determinants Of Carbon Emission Disclosure In Manufacturing 
Companies In Indonesia. International Journal of Energy Economics and Policy, 8(1), 55-61.

Inastri, M. A., \& Mimba, N. P. S. H. (2017). Pengaruh Penerapan Good Corporate Governance Dan Pengungkapan Corporate Social Responsibility Pada Nilai Perusahaan. E-Jurnal Akuntansi, 21(2), 1400-1429. https:// doi.org/10.24843/EJA.2017.v21.i02.p20

Irmayanti, K. N. D., \& Mimba, N. P. S. H. (2018). Pengaruh Profitabilitas, Leverage Dan Kepemilikan Asing Pada Pengungkapan Corporate Social Responsibility Dengan Ukuran Perusahaan Sebagai Variabel Moderasi. E-Jurnal Akuntansi, 23(3), 1932-1954. https:// doi.org/10.24843/EJA.2018.v23.i03.p12

Jaggi, B., Allini, A., Macchioni, R., \& Zagaria, C. (2017). The Factors Motivating Voluntary Disclosure Of Carbon Information: Evidence Based On Italian Listed Companies. Organization and Environment, 31(2), 178-202. https:// doi.org/10.1177/1086026617705282

Kementerian Lingkungan Hidup dan Kehutanan. (2019). Laporan Inventarisasi Gas Rumah Kaca dan Monitoring, Pelaporan Verifikasi Tahun 2018. Diakses pada 2 Juli 2019, dari http:/ / ditjenppi.menlhk.go.id/igrk/lap_igrk_2019.pdf.

Kılıç, M., \& Kuzey, C. (2019). The Effect Of Corporate Governance On Carbon Emission Disclosures: Evidence From Turkey. International Journal of Climate Change Strategies and Management, 11(1), 35-53. https:// doi.org/10.1108/IJCCSM-07-2017-0144

Komite Nasional Kebijakan Governance. (2006). Pedoman Umum Good Corporate Governance Indonesia. Diakses pada 22 Maret 2019, dari http://www.ecgi.org/codes/documents/indonesia_cg_2006_id.pdf.

Kusumawardani, I., \& Sudana, I. P. (2017). Faktor-Faktor Yang Mempengaruhi Pengungkapan Corporate Social Responsibility. E-Jurnal Akuntansi, 19(1), 741-770.

Nainggolan, N. E., \& Rohman, A. (2015). Pengaruh Struktur Corporate Governance Terhadap Pengungkapan Lingkungan (Studi Empiris Pada Perusahaan Non-Keuangan Yang Terdaftar Di Bursa Efek Indonesia Periode 2011-2013). Diponegoro Journal of Accounting, 4(2), 190-198.

Nasih, M., Harymawan, I., Paramitasari, Y. I., \& Handayani, A. (2019). Carbon Emissions, Firm Size, And Corporate Governance Structure: Evidence From The Mining And Agricultural Industries In Indonesia. Sustainability (Switzerland), 11(9), 2483-2496. https:// doi.org/10.3390/su11092483

National Aeronautics and Space Administration. (2019). New Studies Increase Confidence in NASA's Measure of Earth's Temperature. Diakses pada 11 Juni 2019, dari https://climate.nasa.fov/news-studies-increaseconfidence-in-nasas-measure-of-earths-temperature/

Niza, T. C., \& Ratmono, D. (2019). Pengaruh Karakteristik Corporate Governance Terhadap Pengungkapan Emisi Gas Rumah Kaca. Diponegoro Journal of Accounting, 8(4), 1-12.

Pratiwi, D. N. (2018). Implementasi Carbon Emission Disclosure Di Indonesia. Jurnal Ilmiah Akuntansi Dan Bisnis, 13(2), 101-112. https:/ / doi.org/10.24843/JIAB.2018.v13.i02.p04 
Rafifah, U. R., \& Ratmono, D. (2015). Pengaruh Mekanisme Corporate Governance Terhadap Pengungkapan Sukarela Laporan Tahunan. Diponegoro Journal of Accounting, 4(3), 475-487.

Roberts, R. W. (1992). Determinants Of Corporate Social Responsibility Disclosure: An Application Of Stakeholder Theory. Accounting, Organizations and Society, 17(6), 595-612.

Salbiah, \& Mukhibad, H. (2018). Carbon Emission Disclosure And Profitability Evidence from Manufacture Companies in Indonesia. KnE Social Sciences, 3(10), 53-67. https:/ / doi.org/10.18502/kss.v3i10.3118

Singal, P. A., \& Putra, I. N. W. A. (2019). Pengaruh Kepemilikan Institusional, Kepemilikan Manajerial, dan Kepemilikan Asing Pada Pengungkapan Corporate Social Responsibility. E-Jurnal Akuntansi, 298(1), 468-484. https:// doi.org/10.24843/EJA.2019.v29.i01.p30

Tamara, I. G. A. A. T. I., \& Budiasih, I. G. A. N. (2020). Pengungkapan Corporate Social Responsibility Disclosure Sebagai Pemoderasi Pengaruh Good Corporate Governance Pada Nilai Perusahaan. E-Jurnal Akuntansi, 30(5), 1221-1232. https:// doi.org/10.24843/EJA.2020.v30.i05.p12

Wulandari, A. A. A. I., \& Sudana, I. P. (2018). Pengaruh Profitabilitas, Kepemilikan Asing, Kepemilikan Manajemen, Dan Leverage Pada Intensitas Pengungkapan Corporate Social Responsibility. E-Jurnal Akuntansi, 22(2), 1445-1472. https:// doi.org/10.24843/EJA.2018.v22.i02.p23 